\title{
(6) OPEN ACCESS \\ Flavour chemicals in a sample of non-cigarette tobacco products without explicit flavour names sold in New York City in 2015
}

\section{- Additional material is published online only. To view please visit the journal online (http://dx.doi.org/10.1136/ tobaccocontrol-2016-053552) \\ ${ }^{1}$ NYC Department of Health and Mental Hygiene, Bureau of Chronic Disease Prevention and Tobacco Control, Long Island City, New York, USA ${ }^{2}$ Department of Chemistry, Portland State University, Portland, Oregon, USA ${ }^{3}$ Department of Civil and Environmental Engineering, Portland State University, Portland, Oregon, USA}

\section{Correspondence to} James F Pankow, Department of Civil and Environmental Engineering, Portland State University, PO 751, Portland Oregon, 97207-0751 USA; pankowj@pdx.edu

Received 24 November 2016 Revised 6 February 2017 Accepted 15 February 2017 Published Online First 11 April 2017

\author{
Shannon M Farley, ${ }^{1}$ Kevin RJ Schroth, ${ }^{1}$ Victoria Grimshaw, ${ }^{1}$ Wentai Luo, ${ }^{2,3}$ \\ Julia L DeGagne, ${ }^{3}$ Peyton A Tierney, ${ }^{3}$ Kilsun Kim, ${ }^{2}$ James F Pankow ${ }^{2,3}$
}

\begin{abstract}
Background Youth who experiment with tobacco often start with flavoured products. In New York City (NYC), local law restricts sales of all tobacco products with 'characterising flavours' except for 'tobacco, menthol, mint and wintergreen'. Enforcement is based on packaging: explicit use of a flavour name (eg, 'strawberry') or image depicting a flavour (eg, a fruit) is presumptive evidence that a product is flavoured and therefore prohibited. However, a tobacco product may contain significant levels of added flavour chemicals even when the label does not explicitly use a flavour name. Methods Sixteen tobacco products were purchased within NYC in 2015 that did not have explicit flavour names, along with three with flavour names. These were analysed for 92 known flavour chemicals plus triacetin by gas chromatography/mass spectrometry.
\end{abstract}

Results 14 of the 16 products had total determined flavour chemical levels that were higher $(>0.3 \mathrm{mg} / \mathrm{g}$ ) than in previously studied flavour-labelled products and of a chemical profile indicating added flavour chemicals. Conclusions The results suggest that the tobacco industry has responded to sales restrictions by renaming flavoured products to avoid explicitly identifying them as flavoured. While chemical analysis is the most precise means of identifying flavours in tobacco products, federal tobacco laws pre-empt localities from basing regulations on that approach, limiting enforcement options. If the Food and Drug Administration would mandate that all tobacco products must indicate when flavourings are present above a specific level, local jurisdictions could enforce their sales restrictions. A level of $0.1 \mathrm{mg} / \mathrm{g}$ for total added flavour chemicals is suggested here as a relevant reference value for regulating added flavour chemicals in tobacco products.

\section{INTRODUCTION}

It is widely recognised that flavoured tobacco products appeal to youth and that youth who experiment with tobacco often start with flavoured products. Tobacco control professionals have therefore identified restrictions on flavoured tobacco products as a policy goal that has potential to reduce youth tobacco use. ${ }^{2}$ Given the importance of reducing the number of children who start to smoke and become addicted to dangerous tobacco products, in September 2009, Congress prohibited flavoured cigarette production, except for menthol, as part of the Family Smoking Prevention and Tobacco Control Act (FSPTCA). ${ }^{3} 4$ Notably, the federal law says a cigarette 'shall not contain, as a constituent...or additive, an artificial or natural flavor.... that is a characterizing flavor of the tobacco product or tobacco smoke'. Note that low levels of flavour additives that do not yield a 'characterising flavour' are neither banned nor more explicitly defined. The FSPTCA does authorise the Food and Drug Administration (FDA) to mandate disclosures to the FDA on constituents, ingredients and additives, which could be used to require disclosures of flavourings for all regulated tobacco products. Currently, the content of those disclosures is not released to the public or local jurisdictions that regulate tobacco products. In a recent editorial in this journal on flavoured tobacco products in the USA, Stanton et al' conclude that "further data across disciplines with rigorous methods are needed to inform policy decisions regarding the regulation of flavours in tobacco products that can reduce initiation of tobacco products, promote cessation of tobacco products among users and ultimately reduce exposure to harmful products to protect population health'.

In October 2009, to extend the protection conferred by the FSPTCA, New York City (NYC) restricted retail sales of tobacco products other than cigarettes (ie, 'OTP') having 'characterising flavours' other than 'tobacco, menthol, mint or wintergreen' as summarised in Box $1 .^{67}$ Electronic cigarette products are not addressed by this law. 'Tobacco bars', a narrow class of food service establishments that have been required to register annually with NYC since 2002 (and currently numbering eight), are not subject to the flavoured tobacco regulation. Consistent with the FSPTCA, the NYC ordinance defined 'flavored' as 'contains a constituent that imparts a characterizing flavor'. ${ }^{7}$ The ordinance further states that a 'public statement or claim made or disseminated by the manufacturer of a tobacco product...that such tobacco product has or produces a characterizing flavor shall constitute presumptive evidence that the tobacco product is a flavored tobacco product'. As a result of this provision, tobacco product packaging labelled with the name of a flavour, or a picture connoting that flavour-such as 'strawberry', or a picture of a strawberry, constitutes presumptive evidence that sale of the product is illegal in NYC. Several other local jurisdictions have enacted laws restricting the sale of flavoured OTP; these include Providence, Rhode Island; Minneapolis, Minnesota; Chicago, Illinois; Boston, Massachusetts, and various smaller Massachusetts towns. Most of these localities, like NYC, rely on product names as the primary means of identifying flavoured products.
Schroth KRJ Grimshaw $V_{1}$

et al. Tob Control

2018:27:170-176. 


\section{Box 1}

New York City ordinance approved 14 October 2009: 'A local law to amend the New York City charter and the administrative code of the city of New York, in relation to the regulation of tobacco products: Int 0433-2006'. (Upheld in Federal Court: US Smokeless Tobacco Manufacturing Company LLC et al v. City Of New York, Docket No. 11-5167-cv. Decided 26 February 2013 in the United States Court of Appeals, Second Circuit).

Definitions in the ordinance

'Flavored tobacco product' means any tobacco product or any component part thereof that contains a constituent that imparts a characterizing flavor.

'Characterizing flavor' means a distinguishable taste or aroma, other than the taste or aroma of tobacco, menthol, mint or wintergreen, imparted either prior to or during consumption of a tobacco product or component part thereof, including, but not limited to, tastes or aromas relating to any fruit, chocolate, vanilla, honey, candy, cocoa, dessert, alcoholic beverage, herb or spice, provided; however, that no tobacco product shall be determined to have a characterizing flavor solely because of the use of additives or flavorings or the provision of ingredient information.

Banned in the ordinance

\$17-715 Sale of flavored tobacco products prohibited. It shall be unlawful for any person to sell or offer for sale any flavored tobacco product except in a tobacco bar.

Enforcement of the NYC law began in November 2010, and citations for violations have been based on use of explicit flavour names and/or images on the packages. Some NYC retailers, however, are now selling colourfully packaged tobacco products that, although not carrying explicit flavour indicators, smell distinctly of flavour variations other than tobacco, menthol, mint or wintergreen. Although cigarillos labelled 'Blueberry' and 'Strawberry' have largely disappeared from store shelves, noticeably flavoured 'Blue' and 'Pink' cigarillos are increasingly common in NYC. Cigarillos under the brand name Show, labelled 'Ba Boom', are sold in green/black/orange packages. Bluntville branded 'Piff' cigarillos are sold in purple packages, 'blunt' and 'piff' having cannabis connotations. Although NYC rules pertaining to the flavour prohibition allow for sensory testing to identify flavoured products, this enforcement mechanism has not been used to date. Nationally, Viola et $a l^{8}$ note that 'the cigar industry may be pre-emptively steering away from overt flavour descriptors, instead relying on more generic names on their packaging in anticipation of a [federal] ban on flavoured cigars'. Manufacturers may also be anticipating a proliferation of local sales restrictions on flavoured products, taking advantage of the commercial convenience of selecting names that can be used in any jurisdiction. Also, it cannot be excluded that some manufacturers may simply believe that there is consumer demand for products with colourful or catchy names that do not explicitly reference flavours, though for cigarettes, Lempert and Glantz ${ }^{9}$ present arguments that tobacco companies do use colour on packaging and labelling as a replacement for now-prohibited descriptive words such as 'light' and 'mild'.

During a media-briefing conference call on 5 May 2016, ${ }^{10}$ and in regulations published on 10 May, 2016, ${ }^{11}$ the FDA stated that it anticipates issuing a proposed rule that extends its ban on flavoured cigarettes to also prohibit flavoured cigars. It is reasonable to consider that the proposed rule might track the language that prohibits flavoured cigarettes, saying a cigar 'shall not carry a characterizing flavor', as well as requiring cigar manufacturers to disclose product constituents/additives information to the FDA. However, Viola et $a l^{8}$ nevertheless caution that: 'An appropriate definition for 'characterising flavours' that takes into account product ingredients may be necessary to fully capture cigar products that are distinctly flavoured'.

Here we describe the results of a study in which 19 tobacco products purchased in NYC were subjected to chemical analyses to determine the extent to which common non-cigarette tobacco products not labelled as containing flavours contain flavour chemicals. The levels found are compared both within the group, and relative to levels previously measured by Brown et $a l^{12}$ for tobacco products carrying explicit flavour names.

\section{METHODS}

A convenience sample of 16 non-cigarette tobacco products without explicit flavour names were purchased within NYC in February and March 2015 (table $1 \mathrm{a}, \mathrm{b}$ ). Three additional products with flavour names were purchased: (1) Skoal 'Citrus' moist snuff; (2) Black and Mild 'Cream' 'pipe-tobacco cigars' and (3) Camel 'Frost' Snus. The law explicitly applies to tobacco products with 'tastes or aromas relating to any fruit [or] ... dessert'. Because 'citrus' is associated with fruits, and cream is associated with desserts, and a product's name is a 'public statement or claim' suggesting the product is flavoured, the first two products are covered by the law as presumptively flavoured tobacco products. ${ }^{13}$ The 'frost' product is not presumptively prohibited under the NYC regulations as it is not distinctly a dessert, fruit, herb or spice name, and even if it were argued to be a unique characterising flavour, a counterargument could be made that it is more akin to products that fall under the menthol exception than presumptively flavoured tobacco products.

Photographic images of the 19 packages of tobacco product samples were recorded (see online supplementary figures S1 to S5). Each of the 19 products was analysed in triplicate. For each analysis, approximately $1.0 \mathrm{~g}$ was weighed into a $40 \mathrm{~mL}$ glass phial, then spiked with $50 \mu \mathrm{L}$ of a surrogate standard (SS) solution of 1,3,5-triclorobenzene in methanol at $4880 \mathrm{ng} / \mu \mathrm{L}$. For cigars and cigarillos, each $1.0 \mathrm{~g}$ sample was cut from the centre of a complete rod, and so included the wrap and the filler. For snus and snuff products, $1.0 \mathrm{~g}$ of the loose product was used. For products of the pouch type, one pouch was extracted. Ten millilitres of high-purity methanol was then added to the phial. After extraction for 2 hours (with shaking), each phial was allowed to sit for 10 hours to allow separation of the methanol solution from the tobacco material. One millilitre of the extract was placed in a $2 \mathrm{~mL}$ autosampler phial and spiked with $20 \mu \mathrm{L}$ of an internal standard (IS) solution of 1,2,3-trichlorobenzene at $1000 \mathrm{ng} / \mu \mathrm{L}$ in methanol. Each IS-spiked extract was analysed by gas chromatography/mass spectrometry (GC/MS) using an Agilent (Santa Clara, California, USA) 7693 autosampler, Agilent 7890A GC and Agilent 5975 C MS. The GC column type was Restek (Bellefonte, Pennsylvania, USA) Rxi-5Sil MS, of $30 \mathrm{~m}$ length, $0.25 \mathrm{~mm}$ i.d. and $0.25 \mathrm{~mm}$ film thickness. For each sample, $1.0 \mu \mathrm{L}$ was injected with a $15: 1$ split. The GC temperature programme for all analyses was: $35^{\circ} \mathrm{C}$ hold for $5 \mathrm{~min} ; 10^{\circ} \mathrm{C} / \mathrm{min}$ to $300^{\circ} \mathrm{C}$, then hold for $3.5 \mathrm{~min}$ at $300^{\circ} \mathrm{C}$. The MS source temperature was $250^{\circ} \mathrm{C}$. The MS was operated in the electron impact ionisation mode with an ionisation potential of $70 \mathrm{eV}$, with scanning from 34 to 400 atomic mass units.

The analyses were carried out using authentic standards for 93 compounds comprising the target analyte list. This list included 


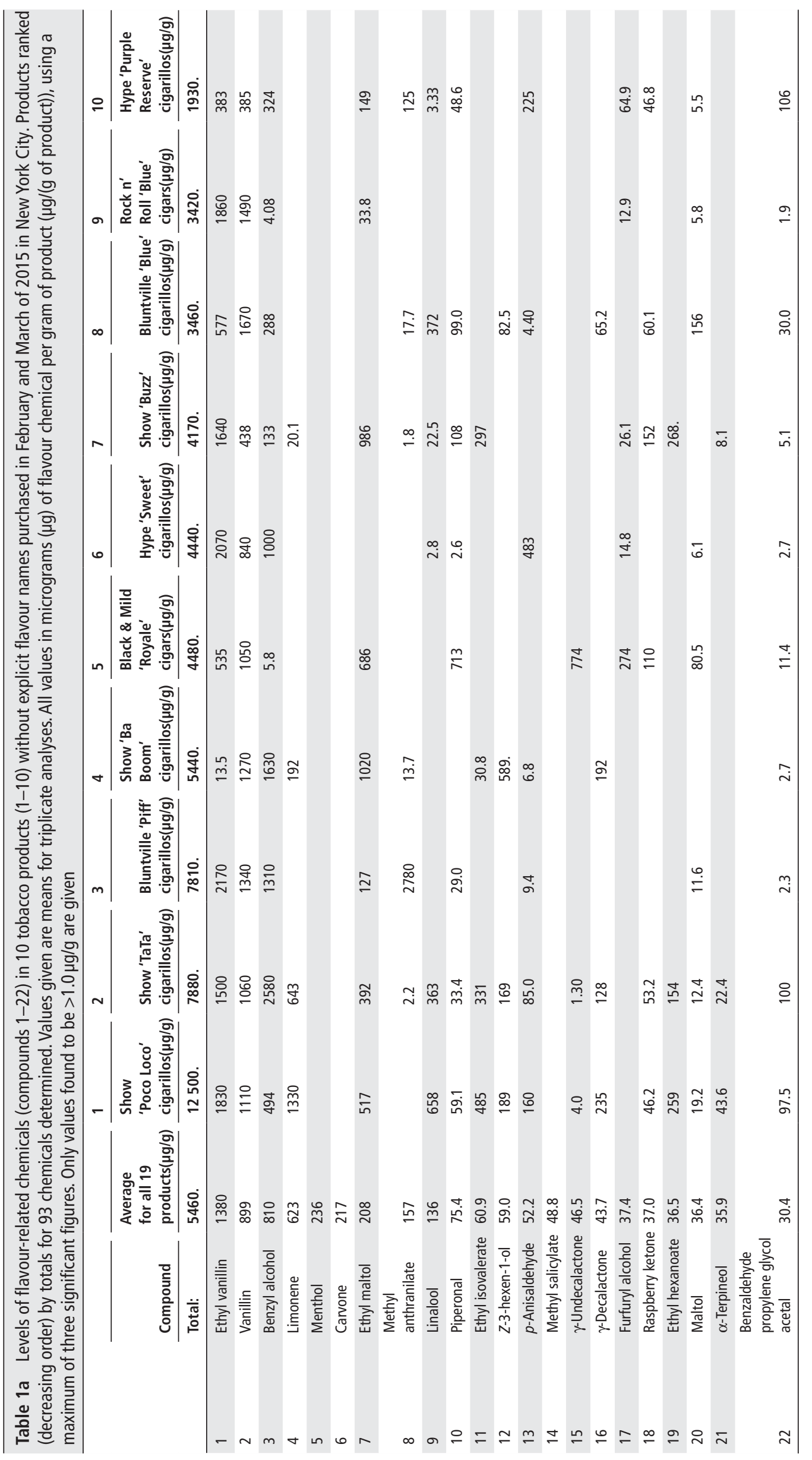




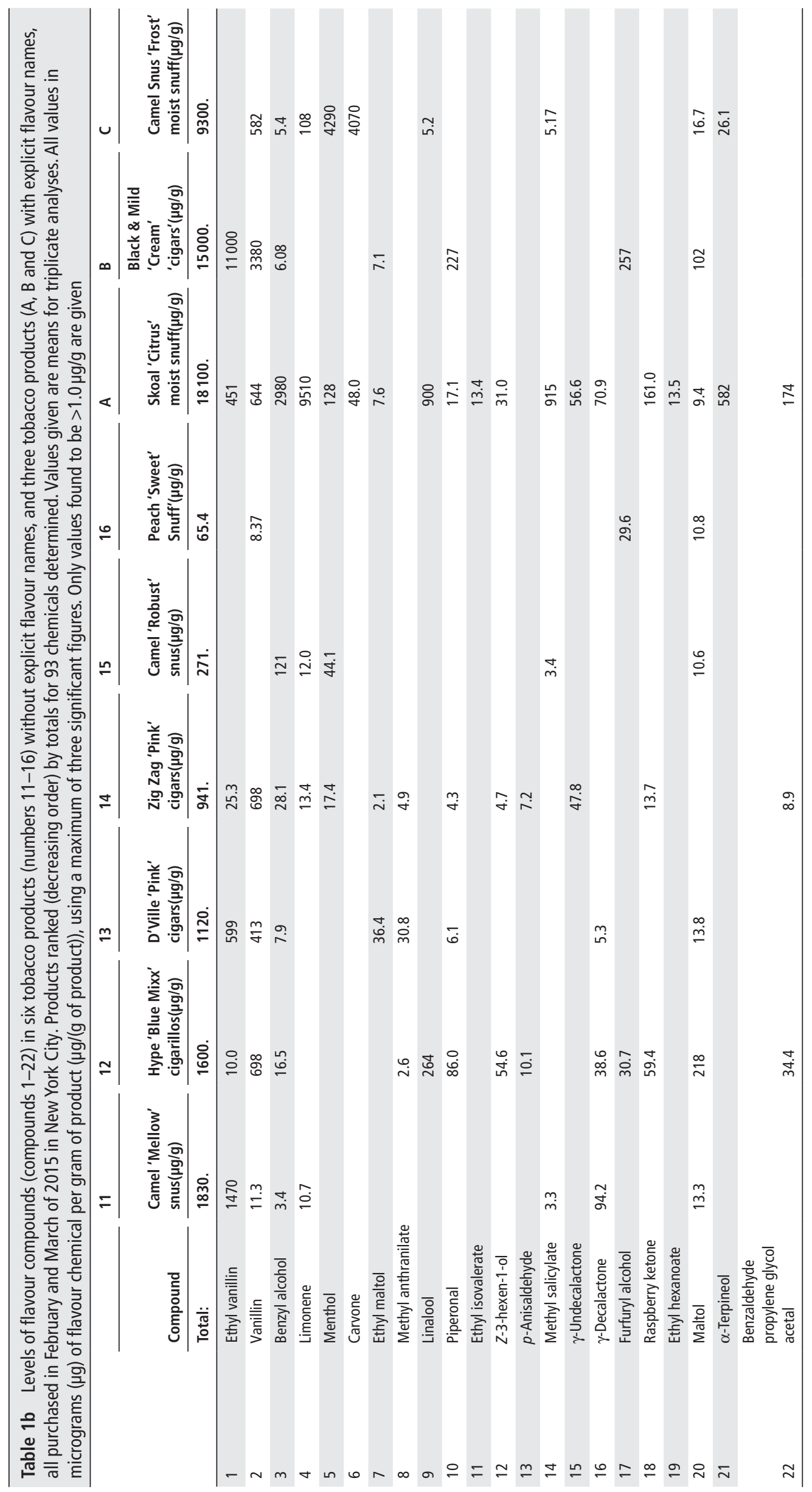




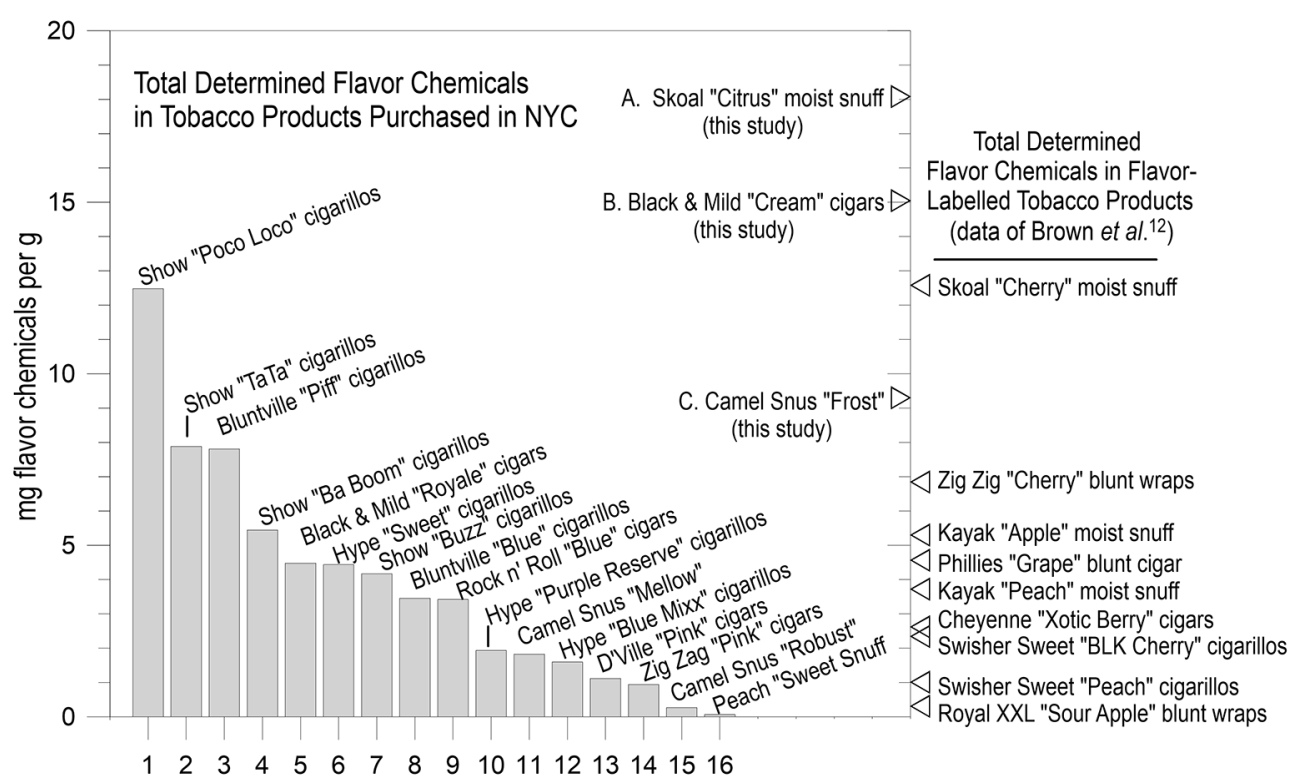

Figure 1 Results for 16 products without explicit flavour names in bar plot form; the values for three products with flavour names examined in this study (A, B and C) are included for comparison. Additional values for reference are for products with explicit flavour names as derived from Brown et $a^{12}$ (see also table 1b). NYC, New York City.

diacetyl (2,3-buanedione), acetyl propionyl (2,3-pentanedione) and triacetin, plus the 90 compounds selected by Tierney $e t \mathrm{al}^{14}$ based on analyses of a range of electronic cigarette fluids. As usual for analyses by GC/MS: (1) the confirmed presence of a given analyte in a particular sample required a match between the sample run and a standard for both: (a) the GC retention time and (b) the MS fragmentation pattern; and (2) quantitation proceeded by comparison with calibration standard runs. Values $>1 \mu \mathrm{g} / \mathrm{g}(0.001 \mathrm{mg} / \mathrm{g})$ are reported here.

\section{RESULTS}

The calculated SS extraction recoveries ranged from $85.7 \%$ to $108.1 \%$; the average recovery $\pm 1 \mathrm{SD}$ was $96.4 \% \pm 5.0 \%$. For the

\begin{tabular}{ll}
\hline $\begin{array}{l}\text { Table } 2 \text { Values derived from Brown et al } \\
\text { flavour names, recomputed from amount 'per serving' to } \mu \mathrm{g} \text { per } \mathrm{g} \\
\text { tobacco product }\end{array}$ \\
\hline Product & Total flavour concentration $(\boldsymbol{\mu g} / \mathbf{g})$ \\
\hline Skoal 'Cherry' moist snuff & 12600 \\
\hline Skoal 'Berry Blend' moist snuff & 11200 \\
\hline Zig Zag Wraps 'Cherry' blunt wraps & 6840 \\
\hline Kayak 'Apple' moist snuff & 5300 \\
\hline Zig Zag Wraps 'Grape' blunt wraps & 5300 \\
\hline Cheyenne 'Wild Cherry' " large cigars' & 5130 \\
\hline Kayak 'Grape' moist snuff & 5080 \\
\hline Phillies Blunt 'Grape' cigar & 4560 \\
\hline Zig Zag Wraps 'Apple' blunt wraps & 4430 \\
\hline Kayak 'Peach' moist snuff & 3720 \\
\hline Cheyenne 'Grape' " large cigars' & 3480 \\
\hline Zig Zag Wraps 'Blueberry' blunt wraps & 3450 \\
\hline Skoal 'Apple' moist snuff & 2790 \\
\hline Cheyenne 'Xotic Berry' 'large cigars' & 2630 \\
\hline Swisher Sweet 'BLK Cherry' cigarillos & 2340 \\
\hline Swisher Sweet 'Peach' cigarillos & 1010 \\
\hline Cheyenne 'Peach' 'large cigars' & 571 \\
\hline Royal Blunt XXL 'Sour Apple' blunt wraps & 313 \\
\hline
\end{tabular}

sample of each product, the coefficient of variation (CV) was calculated for the triplicate process subsampling the product, extracting with solvent, then conducting analysis by GC/MS . The mean $\mathrm{CV} \pm 1 \mathrm{SD}$ was $5.4 \% \pm 3.3 \%$ for determinations larger than $1000 \mu \mathrm{g} / \mathrm{g}, 5.2 \% \pm 3.0 \%$ for determinations between 100 and $1000 \mu \mathrm{g} / \mathrm{g}$ and $9.9 \% \pm 7.1 \%$ for determinations lower than $100 \mu \mathrm{g} / \mathrm{g}$. Sixty-three of the 93 target compounds were detected in the 19 samples at levels ranging from $1 \mu \mathrm{g} / \mathrm{g}$ to $11000 \mu \mathrm{g} / \mathrm{g}$.

The results are summarised in table $1 \mathrm{a}, \mathrm{b}$, online supplementary tables S1.a and S1.b and figure 1. Of the 16 products without explicit flavour names, the two with the lowest total determined flavour chemicals levels were Camel brand 'Robust' snus (\#15) at $271 \mu \mathrm{g} / \mathrm{g}(0.271 \mathrm{mg} / \mathrm{g})$ and Peach brand 'Sweet Snuff' (\#16) at $65 \mu \mathrm{g} / \mathrm{g}(0.065 \mathrm{mg} / \mathrm{g})$. The differences in the flavour profiles of these two products versus those of products \#1 to \#16 can be surmised based on table $1 \mathrm{a}$, b. The common peach flavour compounds $\gamma$-decalactone and $\gamma$-undecalactone were not found in Peach brand 'Sweet Snuff' (\#16). Therefore, absent additional information, manufacturing of at least the latter may not have involved addition of flavour chemicals of the type considered here. However, for Zig Zag 'Pink' cigars (\#14), the total determined flavour chemical level was $941 \mu \mathrm{g} / \mathrm{g}(0.941 \mathrm{mg} / \mathrm{g})$, with vanillin at $698 \mu \mathrm{g} / \mathrm{g}(0.698 \mathrm{mg} / \mathrm{g})$. It is certain that the $\mathrm{Zig}$ Zag 'pink' cigars (\#14) were intentionally flavoured given that natural levels of vanillin in a range of types of tobacco leaf have been reported to be in the range $0.9-1.8 \mu \mathrm{g} / \mathrm{g} .{ }^{15}$ The product with the highest level of total flavour chemicals was Show 'Poco Loco' cigarillos (\#1) at $12500 \mu \mathrm{g} / \mathrm{g}(12.5 \mathrm{mg} / \mathrm{g})$.

The results for products 1 to 16 (ie, those without explicit flavour names) are plotted in figure 1; the values for the three products (A, B and C) with flavour names are included for reference, along with values derived from Brown, et $a l^{12}$ for analyses (also by extraction then GC/MS) of multiple tobacco products with explicit flavour names (see table 2).

\section{DISCUSSION}

Tobacco products without explicit flavour names that have been available for purchase in NYC are, in fact, flavoured. Fourteen 
out of 16 products without explicit flavour names were found to contain total flavour chemical levels higher than the lowest level product with an explicit flavour name examined previously ${ }^{12}$ (Royal XXL 'Sour Apple' blunt wraps, $0.313 \mathrm{mg} / \mathrm{g}$; table 2). The results suggest that the tobacco industry may have anticipated or responded to restrictions on the sale of flavoured products by introducing flavoured products without characterising flavour names, using packaging to imply that certain products are flavoured.

As noted above, in May 2016, the FDA exercised its authority to expand the range of tobacco products subject to its regulatory authority by deeming the definition of tobacco products to include cigars, tobacco-containing shisha smoked in hookah pipes, pipe tobacco, e-cigarettes and liquid e-cigarette refills and more. ${ }^{11}$ The FDA will thereby require manufacturers of these products to report on constituents, ingredients and additives. The FDA also announced that it plans to issue proposed rules that would extend its ban on 'characterising flavours' for cigarettes to cover cigars. Presumably, such a ban could not be sidestepped simply by removing flavour names from packages. Even with a federal prohibition on the production of flavoured cigars, other flavoured tobacco would still be marketed and sold (smokeless tobacco, pipe tobacco and shisha). For those products, local jurisdictions such as NYC with restrictions on the sale of flavoured products would still confront the challenge of identifying flavoured tobacco products when the label does not explicitly reference a flavour (local jurisdictions are pre-empted from regulating tobacco manufacturing processes and cannot address product ingredients directly).

The FDA deeming rules subject OTPs to federal regulations, including reporting requirements on constituents, ingredients and additives. However, local jurisdictions are not privy to such information. As a result, localities may still be reliant on labelling information to identify flavoured products which, as this paper demonstrates, may be an underinclusive approach. If the FDA were to require manufacturers to label tobacco products as 'flavoured' when they have greater than a specific maximum permissible added level of certain ingredients, local jurisdictions would be able to enforce sales restrictions more effectively.

Because the products examined here were obtained as a convenience sample, all study-relevant tobacco products available in NYC in 2015 were not analysed. Nevertheless, the results indicate that the samples ranged from some that were clearly overtly flavoured to others that had low overall flavour levels, and so the study-relevant range of flavour levels has probably been correctly identified. Second, the number of flavour-related target analyte chemicals was capped at 93. Nevertheless, although some added flavour compounds present in the samples may have thus escaped being reported on this work, as noted above, none of these contributed in a major way to any given sample.

The establishment of any particular regulatory level for total added flavour chemicals vis a vis the term 'characterizing flavour' is notably complicated by variable sensitivity among the population in detecting flavour chemicals (eg, see Deems ${ }^{16}$ ), compound-by-compound variability in odour potency, compound-by-compound inherent variability in volatility, which is required for odour detection, and dependence of flavour compound volatility on product type (eg, products of different water contents). Nevertheless, we propose that some specific level for total added flavour chemicals be considered as the demarcation for 'characterizing flavour'. A level such as $0.1 \mathrm{mg} / \mathrm{g}$ or lower might be considered. It is: (1) $\sim 1 / 3$ the $0.313 \mathrm{mg} / \mathrm{g}$ value for total determined flavour chemicals found by Brown et
What this paper adds

- New York City (NYC) currently prohibits sales of tobacco products having 'characterising flavours' other than 'tobacco, menthol, mint or wintergreen', except as may occur in 'tobacco bars'. Enforcement action may take place when products are explicitly labelled with a recognisable flavour name (eg, cherry and vanilla) or flavour image (eg, fruit and candy). Chemical testing of products cannot be used as a basis for enforcement by a state or local jurisdiction because federal law pre-empts local regulations based on tobacco product standards (eg, a city or state likely cannot ban specific flavourings based on chemical analyses).

- A convenience sample of 19 tobacco products were purchased in NYC in 2015. Sixteen tobacco products did not have explicit flavour names. All products were analysed by gas chromatography/mass spectrometry. Fourteen tobacco products were found to contain total determined flavour chemical levels higher than the lowest total level $(0.313 \mathrm{mg} / \mathrm{g})$ found in 18 tobacco products with flavour names previously analysed by our laboratory.

- The results indicate that most (if not all) of the 14 have a 'characterising flavour', likely constituting a violation of the NYC ordinance: manufacturers may be responding to local adoption of laws restricting the sale of flavoured products by avoiding explicit flavour names.

- The Food and Drug Administration (FDA) has announced a plan to prohibit flavoured cigars. Such a step would advance local efforts to reduce availability of flavoured 'other tobacco products' (OTPs), although localities that restrict the sale of flavoured OTPs would still contend with enforcement challenges related to flavoured smokeless tobacco, pipe tobacco and tobacco-containing shisha.

- This work suggests that the FDA could consider using its unique power to regulate ingredients and flavourings to help local jurisdictions enforce their restrictions on the sale of flavoured tobacco products. For example, the FDA could decide to require all tobacco products with more than some particular total number of milligrams of total flavour chemicals per gram of product to bear a disclosure on their label stating 'This is a flavoured tobacco product'.

$a l^{12}$ to have been used in the admittedly 'apple'-flavoured Royal Blunt XXL 'Sour Apple' blunt wraps (see tables $1 \mathrm{a}, \mathrm{b}$ ); and (2) of the same magnitude found here for Peach brand (but not peach flavoured) 'Sweet Snuff' $(0.065 \mathrm{mg} / \mathrm{g})$. Some will object to a suggested level of $0.1 \mathrm{mg} / \mathrm{g}$, given the large range of flavour chemicals used in foods and beverages (see Burdock ${ }^{17}$ ). Moreover, distinguishability by smell relative to tobaccos without any added flavour chemicals will be likely possible for some of the chemicals at values lower than $0.1 \mathrm{mg} / \mathrm{g}$. However, given that portions of the US tobacco industry readily acknowledge use of chemicals as flavour additives (including in cigarettes), ${ }^{18}$ many (if not most) tobacco products are already distinguishable by smell from unflavoured tobacco. Consequently, stricter regulations on levels of total added flavour chemicals may not require or be enhanced by the continued use of the term 'characterizing flavour'. Last, revisions to regulatory levels are always possible and have been implemented numerous times for ambient atmospheric pollutants: for example, the regulatory value for the 8 -hour average for ozone in the USA was set at $0.080 \mathrm{ppb}$ in 
1997, $0.075 \mathrm{ppb}$ in 2008 and $0.070 \mathrm{ppb}$ in 2015 (all values are parts per billion (ppb) by volume in air). ${ }^{19}$

Correction notice This article has been corrected since it was published Online First. The "Correspondence to" address has been corrected.

Acknowledgements The authors thank Dr Shadi Chamany for her valuable input during internal review.

Contributors JFP and SMF planned the study. SMF, VG and KRJS planned and reviewed the selection process by which the tobacco products were obtained; KRJS reviewed the legal aspects of the study. WL, JLD, PAT and KK carried out the analyses. WL managed the data quality assurance/quality control (QA/QC) processes. The manuscript was drafted by JFP with assistance from SMF, KRJS and VG. All authors reviewed the manuscript.

Funding Funding for this work was provided by the Cooley Family Fund for Critical Research of the Oregon Community Foundation and by the Fariborz Maseeh Professorship at Portland State University.

Competing interests None declared.

Patient consent No patients or human subjects were involved in this study.

Provenance and peer review Not commissioned; externally peer reviewed.

Open Access This is an Open Access article distributed in accordance with the Creative Commons Attribution Non Commercial (CC BY-NC 4.0) license, which permits others to distribute, remix, adapt, build upon this work non-commercially, and license their derivative works on different terms, provided the original work is properly cited and the use is non-commercial. See: http://creativecommons.org/ licenses/by-nc/4.0/

(c) Article author(s) (or their employer(s) unless otherwise stated in the text of the article) 2018. All rights reserved. No commercial use is permitted unless otherwise expressly granted.

\section{REFERENCES}

1 Ambrose BK, Day HR, Rostron B, et al. Flavored tobacco product use among US youth aged 12-17 years, 2013-2014. JAMA 2015;314:1871-3.

2 Farley SM, Johns M. New York city flavoured tobacco product sales ban evaluation. Tob Control; Published Online First 12 February 2016.

3 GPO Family Smoking Prevention and Tobacco Control Act. Public law 111-31. June 22, 2009. http://www.gpo.gov/fdsys/pkg/PLAW-111 publ31/pdf/PLAW-111 publ31.pdf (accessed 8 Nov 2015).
4 FDA News Release. Candy and fruit flavored cigarettes now illegal in United States; Step is first under new tobacco law. Sept 22, $2009 \mathrm{http}: / / \mathrm{www}$. fda.gov/NewsEvents/ Newsroom/PressAnnouncements/ucm 183211.html (accessed 20 Nov 2016).

5 Stanton CA, Villanti AC, Watson C, et al. Flavoured tobacco products in the USA: synthesis of recent multidiscipline studies with implications for advancing tobacco regulatory science. Tob Control 2016;25:ii1-3.

6 A local law to amend the New York city charter and the administrative code of the city of New York, in relation to the regulation of tobacco products. October 28,2009. Int 0433-2006.

7 New York City Administrative Code, Title 17. Health. Chapter 7. Regulation of tobacco products. https://www1.nyc.gov/assets/dca/downloads/pdf/about/retail_cigarette_ dealer_law_rules.pdf (accessed 20 Nov 2016).

8 Viola AS, Giovenco DP, Miller Lo EJ, et al. A cigar by any other name would taste as sweet. Tob Control 2016;25:605-6.

9 Lempert LK, Glantz S. Packaging colour research by tobacco companies: the pack as a product characteristic. Tob Control; Published Online First 12 February 2016.

10 Food and Drug Administration (FDA). Media briefing on final rule extending tobacco authority to additional tobacco products, moderator: Michael Felberbaum, May 5, 2016. Transcript. http://www.fda.gov/downloads/NewsEvents/Newsroom/ MediaTranscripts/UCM499834.pdf (accessed 6 Jan 2017).

11 Food and Drug Administration (FDA). Deeming tobacco products to be subject to the Federal Food, drug, and Cosmetic Act, as amended by the family smoking prevention and tobacco 21 CFR Parts 1100, 1140, and 1143. May 2016 https://www.govinfo. gov/content/pkg/FR-2016-05-10/pdf/2016-10685.pdf (accessed 20 Nov 2016).

12 Brown JE, Luo W, Isabelle LM, et al. Candy flavorings in tobacco. N Engl J Med 2014:370:2250-2

13 New York City Health Code, Title 24, Chapter 28 restriction on the sale of certain flavored tobacco products § 28-03 - Presumptively Flavored Tobacco Products. https:// www1.nyc.gov/site/doh/about/about-doh/health-code-and-rules.page (accessed 3 Feb 2017).

14 Tierney PA, Karpinski CD, Brown JE, et al. Flavour chemicals in electronic cigarette fluids. Tob Control: Published Online First 15 April 2015.

15 Demian BA. Trace analysis of vanillin in tobacco. J Liq Chromatogr 1993;16:3563-74.

16 Deems DA, Doty RL. Age-related changes in the phenyl ethyl alcohol odor detection threshold. Trans Pa Acad Ophthalmol Otolaryngol 1987;39:646-50.

17 Burdock GA. Fenaroli's handbook of flavor ingredients. 6th edn. Boca Raton, FL: CRC Press, Taylor and Francis Group, 2010.

18 Philip Morris USA. Our products \& ingredients. http://www.altria.com/our-companies/ philipmorrisusa/our-products-and-ingredients/Pages/default.aspx (accessed 12 Jan 2017).

19 US Environmental Protection Agency. Table of historical ozone national ambient air quality standards (NAAQS), History of the NAAQS for ozone, from 1971 to 2015. https://www.epa.gov/ozone-pollution/table-historical-ozone-national-ambient-airquality-standards-naaqs (accessed 12 Jan 2017). 